\title{
Comparative three way analysis of biochemical responses in cereal and millet crops under salinity stress
}

\author{
Ritika Bhatt ${ }^{1}$, Prem Prakash Asopa ${ }^{1}$, Santosh Sihag ${ }^{1}$, Rakesh Sharma ${ }^{1}$, Sumita Kachhwaha ${ }^{1}$, S.L. Kothari ${ }^{1,2}{ }^{2}$ \\ ${ }^{1}$ Department of Botany, University of Rajasthan, Jaipur, Rajasthan-302004, India. \\ ${ }^{2}$ Institute of Biotechnology, Amity University Rajasthan, Jaipur-302019, India.
}

\section{ARTICLE INFO}

Article history:

Received on: 18/10/2015

Revised on: 01/11/2015

Accepted on: 24/11/2015

Available online: 19/12/2015

Key words:

Antioxidants, LDA, PCA,

ROS, Salinity.

\begin{abstract}
Cereals and millets account for staple food of the major population of the world and any stress posed on them limits their productivity. Salt stress affects seed germination and results in poor grain quality and low production. To identify the best responding cereal against variable salinity regime, the present study was undertaken. The seeds were grown under salt stress of $0 \mathrm{mM}$ to $200 \mathrm{mM}$ and plantlets were excised on $15^{\text {th }}$ day of the experiment for biochemical analysis. Salinity caused specific changes in the antioxidant potential of the plant as seen through Superoxide Dismutase (SOD), Peroxidase (POX), Catalase (CAT) and Ascorbate peroxidase (APX) enzyme activities. The enzyme activities were calculated through multivariate analysis to ascertain the biochemical responses using Principal component analysis (PCA) and Linear discriminate analysis (LDA). A significant increase in the antioxidative enzyme activity was noted in Eleusine, suggesting that it is better suited to combat the oxidative stress injury amongst the three plants.
\end{abstract}

\section{INTRODUCTION}

Abiotic stress is defined as any environmental factor which influences the optimal functioning of an organism [1]. Cereals face a variety of stresses during their growth and salinity is one of the major stresses which limit the crop production and quality of economically important cereals throughout the world [2]. Salinity is defined as the excess of ions of soluble salts such as sodium $\left(\mathrm{Na}^{+}\right)$, chloride $\left(\mathrm{Cl}^{-}\right)$, calcium $\left(\mathrm{Ca}^{2+}\right)$, sulphate $\left(\mathrm{SO}_{4}{ }^{2-}\right)$ and bicarbonate $\left(\mathrm{HCO}_{3}^{-}\right)$in soil that affect plant growth and development [3]. Salinity has a two-fold effect on plants: the salt in the soil solution decreases the availability of water to the roots, and the salt taken up by the plant can accumulate to toxic levels in certain tissues [4]. The saline growth medium causes many adverse effects on growth, due to a low osmotic potential of soil solution (osmotic stress), specific ion effects (salt stress), nutritional imbalances, or a combination of these factors [5]. All these responses are mainly due to the acerbity of salt stress, inherent salt endurance of the plant and the persistence of the salt exposure to the plant roots [6]. When molecular $\mathrm{O}_{2}$ undergoes reduction, successive one electron reduction forms several byproducts called Reactive Oxygen Species (ROS). It includes singlet oxygen $\left({ }^{1} \mathrm{O}_{2}\right)$, superoxide radical $\left(\mathrm{O}_{2}^{-1}\right)$, hydrogen peroxide $\left(\mathrm{H}_{2} \mathrm{O}_{2}\right)$ and the hydroxyl radical $\left(\mathrm{OH}^{-}\right)$[2]. Though

* Corresponding Author

Mail id: slkothari28@gmail.com, Faxno- +91-141-2703439
ROS are produced under normal growth conditions, their amount enhances during environmental stress conditions. ROS are highly reactive and thus the cells require an extensive protective mechanism which can bypass the disruption of normal metabolism through oxidative damage to lipids, protein and nucleic acids [7], for which a complex defensive antioxidative system has been developed by plants [8] which can be grouped into two classes: (a) non-enzymatic constituents, including polar and non-polar phenols (polyphenols and tocopherols), nitrogen compounds (alkaloids and polyamines), carotenoids, some other compounds (ascorbic acid and geniposidic acid) (b) compartmentalized isozymes, including superoxide dismutase (SOD; EC 1. 15. 1. 1), catalase (CAT; EC 1. 11. 1. 6), peroxidase (POX; EC 1. 11. 1. 7), ascorbate peroxidase (APX; EC 1. 11. 1. 11) and glutathione reductase (GR; EC 1. 6. 4. 2) [9]. Analogy has been established between salt stress and ROS production in several studies reported on cereals and millets like maize [10] and finger millet [11].

However, specific mechanisms that impart salt-tolerance to crop plants are still to be explicated. The studies on comparative analyses of salinity dependent antioxidant species production between different cereals are at a setback. This study was therefore, attempted to analyze and compare the in vitro responses of three cereal species to elucidate the best responding cultivars amongst the three, which may thereby prove to be a boon as the staple food crop in the salt affected areas. The study may be further taken up to genetically transform the food crop for enhanced production of antioxidant species and limited ROS production. 


\section{MATERIALS AND METHODS}

\subsection{Plant material and Medium Preparation}

Seeds of Triticum aestivum L. (wheat) were procured from Rajasthan Agricultural Research Station, Durgapura, Jaipur and seeds of Eleusine corcana L. Gaertn (finger millet) and Paspalum scrobiculatum L. (kodo millet) were procured from University Agricultural Sciences, GKVK, Bangalore. Moist filter paper test to check seed viability was conducted for several varieties of all the three plants which included Raj-4120, Raj4037, Raj-3077, Raj-4079, PBW-621, HD-2967, PBW-550, DBW17 for Wheat; KMR 204, RAU-8, TNAU-66, VR-708, MR-6, PR202 for Finger millet, GPUK-3, RBK-155, TNAU 86, RK-390-25 for Kodo millet. MS media was prepared by using Murashige and Skoog medium (Himedia PT021) and was supplemented with 3\% sucrose (Loba chemicals, India). The chloride $\left(\mathrm{Cl}^{-}\right)$dominated salinity was created by making a $1 \mathrm{M}$ solution of $\mathrm{NaCl}$ (Merck, India) and $\mathrm{MgCl}_{2}$ (Fisher Scientific) in a $1: 1$ ratio. Different concentrations of salt were prepared by this solution i.e. $0 \mathrm{mM}, 50$ $\mathrm{mM}, 100 \mathrm{mM}, 150 \mathrm{mM}$ and $200 \mathrm{mM}$ and were added to MS medium. $8 \%$ w/v agar (Bacteriological grade, Merck, India) was added as a gelling agent in the medium. The Seeds were surface sterilized by washing with extran (Liquid detergent, Merck, India) and later by $0.5 \% \mathrm{HgCl}_{2}$ (Merck, India) solution for 3 mins. The seeds were inoculated in the medium with different salt concentrations and kept at $26 \pm 2^{\circ} \mathrm{C}$ with a photoperiod of $16 \mathrm{~h}$ light. Observations were recorded on the fifteenth day and seedlings were excised. The shoot length and root length were measured and various germination parameters calculated.

\subsection{Enzyme extract and Assays}

Enzyme extraction conditions like molarity, $\mathrm{pH}$ and concentration of buffers were standardized. All the procedures were carried out at relative temperature range of $0-4{ }^{\circ} \mathrm{C}$ under aseptic conditions. The excised leaves $(1 \mathrm{~g})$ were homogenized in a pre- chilled mortar and pestle with $10 \mathrm{~mL}$ of ice-cold extraction medium (50mM phosphate buffer $\mathrm{pH} 7.0$ (PB) for POX, CAT and APX and PB containing $0.25 \%$ triton and $1 \%$ polyvinylpyrrolidone for SOD).

The homogenate was centrifuged at $10,000 \times \mathrm{g}$ for $15 \mathrm{~min}$ at $4{ }^{\circ} \mathrm{C}$. The supernatant was used as crude extract for enzyme activity. All the estimations were carried out in three replicates and value reported was thus a mean of three replicates.

\subsection{Enzyme Assays}

Peroxidase activity (POX) was based on the Guaiacol$\mathrm{H}_{2} \mathrm{O}_{2}$ method as described by [12] which measures the change in absorbance at $470 \mathrm{~nm}$ due to oxidation of hydrogen donors in the presence of $\mathrm{H}_{2} \mathrm{O}_{2}$. The assay mixture $(4 \mathrm{ml})$ consisted of $2 \mathrm{ml}$ of (PB), $1 \mathrm{ml}$ enzyme extract (EE), $0.5 \mathrm{ml}$ Guaiacol (1\%). The reaction was started by adding $0.5 \mathrm{ml} \mathrm{H}_{2} \mathrm{O}_{2}(0.5 \%)$. Activity was expressed as $\mathrm{U} \mathrm{gmFW}^{-1} \mathrm{~min}^{-1}$.

Total SOD activity was measured by estimating its ability to inhibit the photochemical reduction of nitrobluetetrazolium chloride (NBT), following the method of [13].The assay mixture $(3 \mathrm{ml})$ contained $2.4 \mathrm{ml}$ of $\mathrm{PB}, 0.1 \mathrm{ml}$ of $13 \mathrm{mM}$ methionine, $0.1 \mathrm{ml}$ of $0.1 \mathrm{mM}$ EDTA, $0.1 \mathrm{ml}$ of $50 \mathrm{mM}$ sodium bicarbonate and $0.1 \mathrm{ml}$ EE. The reaction was initiated by adding $0.1 \mathrm{ml}$ of $2 \mathrm{mM}$ riboflavin and exposing to $15 \mathrm{~W}$ fluorescent light for $10 \mathrm{~min}$. Absorbance was read at $560 \mathrm{~nm}$ and activity was expressed as $\mathrm{U}_{\mathrm{gmFW}}{ }^{-1} \mathrm{~min}^{-1}$. One unit of SOD activity (U) was defined as the amount of enzyme required to cause $50 \%$ inhibition of the NBT.

CAT activity was measured according to the method of [14] with minor modifications. The reaction mixture $(3 \mathrm{ml})$ consisted of $2.7 \mathrm{ml}$ of $\mathrm{PB}$ and $0.1 \mathrm{ml} \mathrm{EE}$. The reaction was started by the addition of $0.2 \mathrm{ml}$ of $200 \mathrm{mM} \mathrm{H}_{2} \mathrm{O}_{2}$. The decrease in absorbance was recorded at $410 \mathrm{~nm}$ for 3 mins. The activity was expressed as $\mathrm{U} \mathrm{gmFW}^{-1} \mathrm{~min}^{-1}$.

Total APX activity was assayed according to [15]. The reaction mixture $(4 \mathrm{ml})$ contained $2 \mathrm{ml} \mathrm{PB}, 0.1 \mathrm{ml}$ of $0.1 \mathrm{mM}$ EDTA, $0.7 \mathrm{ml}$ of $0.5 \mathrm{mM}$ ascorbate and $0.1 \mathrm{ml}$ of $0.1 \mathrm{mM} \mathrm{H}_{2} \mathrm{O}_{2}$. The reaction was started by the addition of $1 \mathrm{ml} \mathrm{EE}$ and absorbance was recorded after $10-30 \mathrm{sec}$ at $290 \mathrm{~nm}$. The activity was expressed as $\mathrm{U}_{\mathrm{gmFW}} \mathrm{min}^{-1}$.

\subsection{Chlorophyll Estimation}

Chlorophyll and carotenoids were extracted and the amounts were calculated with the equations in accordance to [16].

\subsection{Statistical analysis}

The combined dataset of Triticum, Eleusine and Paspalum, used for multivariate modeling consisted of two morphological and four biochemical parameters. The multivariate data modeling was performed using $\mathrm{R}$ version 3.0.1. The experiments were conducted in complete randomized block design. The experiment was repeated in triplicate under identical conditions and values expressed as mean \pm S.D. Analysis of Variance for the design was carried out to detect the significant differences among the treatment means, which were compared using Duncan's multiple range test at the $5 \%$ probability level according to [17].

C50 values for the plants were determined by using 'drc' package [18] of R using concentration as "dose" and shoot length as "response". 'drm' function of 'drc' package uses nonlinear least square curve fitting for estimating the critical lethal concentration. C50 value here, defines the $50 \%$ reduction in the shoot length with increasing salt regime as compared to the length of the control plants.

Principal component analysis was performed by 'prcomp' function of 'stats' package of $\mathrm{R}$ which uses singular value decomposition of (centered and possibly scaled) data matrix, not by using eigen on the covariance matrix and is usually the favored method for numerical accuracy. Linear discriminate analysis (LDA) was performed by 'lda' function of 'MASS' package of R. The purpose of LDA is to find out the linear combination of original variables (two morphological and four biochemical) that gives the best possible separation between the three plants species. 


\section{RESULTS}

\subsection{Morphological and Biochemical analysis}

In the present study all plantlets were excised on the 15th day of germination to analyze the germination parameters. Raj 3077 variety of Triticum aestivum, PR-202 variety of Eleusine coracana and GPUK-3 variety of Paspalum scrobiculatum were found to be the best responding varieties. When germinated in a medium with high salinity, all the plants had stunted growth and the root and shoot lengths demonstrated significant changes with constitutive increase in the salinity strata (fig.1 and fig. 2). The shoot length was affected to a great extent at enhanced salinity levels (fig.2). The calculated results (table 1) showed that salt stress significantly reduced germination parameters. The germination percentage varied significantly amongst the three genera and the ability to germinate declined as the salinity levels increased from $50 \mathrm{mM}$ to $200 \mathrm{mM}$. Amongst the three plants,
Eleusine showed the highest germination percentage (100\%) and relative germination rate at all concentrations. To understand the ROS scavenging mechanism, enzymes of antioxidant system were studied in the crop plants. The SOD activities of the three genera under different salt concentrations reveal that the enzyme activity increased progressively with increasing salt concentration, after 15 days of salt stress application (fig 3 A). Eleusine had higher constitutive enzymatic activity level at all concentrations as compared to its fellow millet species. The POX activity showed a remarkable increase with increasing salinity, unlike the SOD activity. The activity increased significantly in Eleusine (40.36 to 124.60 $\mathrm{U} \mathrm{gmFW}^{-1} \mathrm{~min}^{-1}$ ) and Paspalum (34.13 to $54.41 \mathrm{U} \mathrm{gmFW}^{-1}$ $\mathrm{min}^{-1}$ ) with increasing salt levels (fig $3 \mathrm{~B}$ ). The CAT and APX enzyme activity increased in all the three plants with increasing concentration of the salt (fig. $3 \mathrm{C}, 3 \mathrm{D}$ respectively) and recorded to be highest in Eleusine. The total chlorophyll content of the plant showed a significant decrease in all the three plants (fig $3 \mathrm{E}$ ).

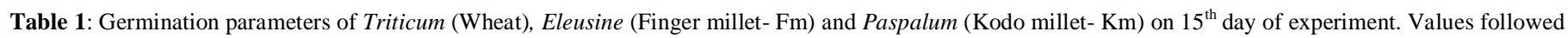

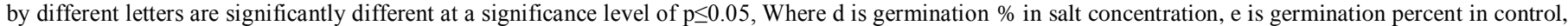
Gt is germinated seeds in $\mathrm{t}$ days (in present study $\mathrm{t}=15$ days), Dt is number of germination days corresponding [30].

\begin{tabular}{|c|c|c|c|c|c|c|c|c|c|c|c|c|}
\hline \multirow[b]{2}{*}{ concentration } & \multicolumn{3}{|c|}{ Germination percentage } & \multicolumn{3}{|c|}{ Relative germination rate $(\mathrm{d} / \mathrm{e})$} & \multicolumn{3}{|c|}{ Relative salt injury(e-d/e) } & \multicolumn{3}{|c|}{ Germination index } \\
\hline & Wheat & Fm & $\mathbf{K m}$ & Wheat & $\mathbf{F m}$ & Km & Wheat & Fm & $\mathbf{K m}$ & Wheat & Fm & Km \\
\hline 0 & $100.0^{\mathrm{a}}$ & $100.0^{\mathrm{a}}$ & $92.6^{\mathrm{c}}$ & & & & & & & 1.47 & 1.87 & 1.67 \\
\hline 50 & $83.3^{\mathrm{g}}$ & $100.0^{\mathrm{a}}$ & $91.7^{\mathrm{d}}$ & 0.83 & 1.00 & 0.99 & 99.17 & 99.00 & 91.60 & 1.33 & 2.33 & 1.47 \\
\hline 100 & $84.0^{\mathrm{f}}$ & $97.1^{\mathrm{b}}$ & $90.0^{\mathrm{e}}$ & 0.84 & 0.97 & 0.97 & 99.16 & 99.03 & 91.62 & 1.40 & 2.27 & 1.80 \\
\hline 150 & $76.0^{\mathrm{h}}$ & $91.4^{\mathrm{d}}$ & $56.7^{\mathrm{j}}$ & 0.76 & 0.91 & 0.61 & 99.24 & 99.09 & 91.98 & 1.27 & 2.13 & 1.13 \\
\hline 200 & $52.0^{\mathrm{k}}$ & $74.3^{\mathrm{i}}$ & $6.7^{1}$ & 0.52 & 0.74 & 0.07 & 99.48 & 99.26 & 92.52 & 0.87 & 1.73 & 0.13 \\
\hline
\end{tabular}

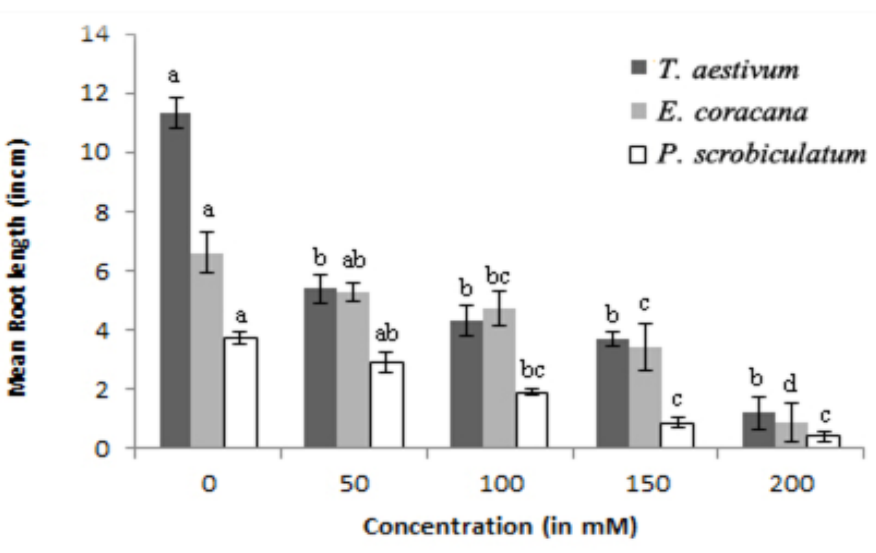

Fig. 1: Root lengths under different salt concentrations.

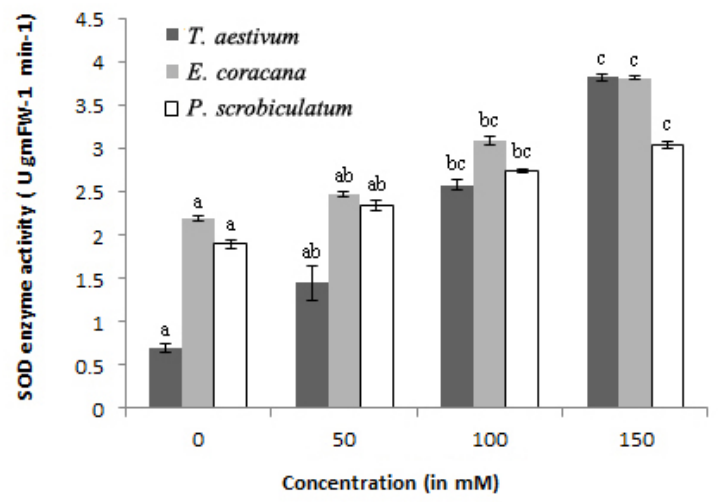

Fig 3A

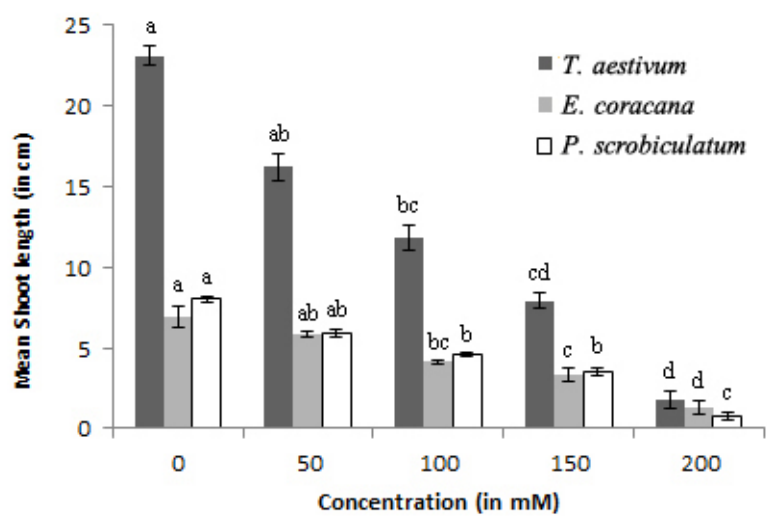

Fig. 2: Shoot lengths under different salt concentrations.

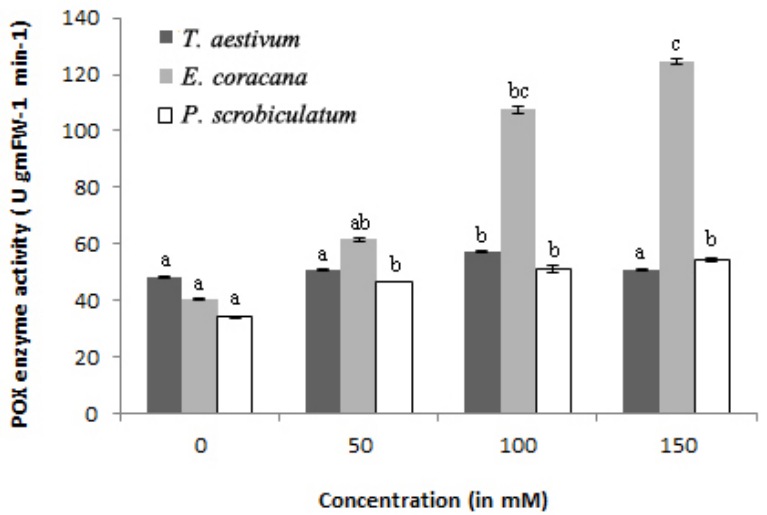

Fig 3B 

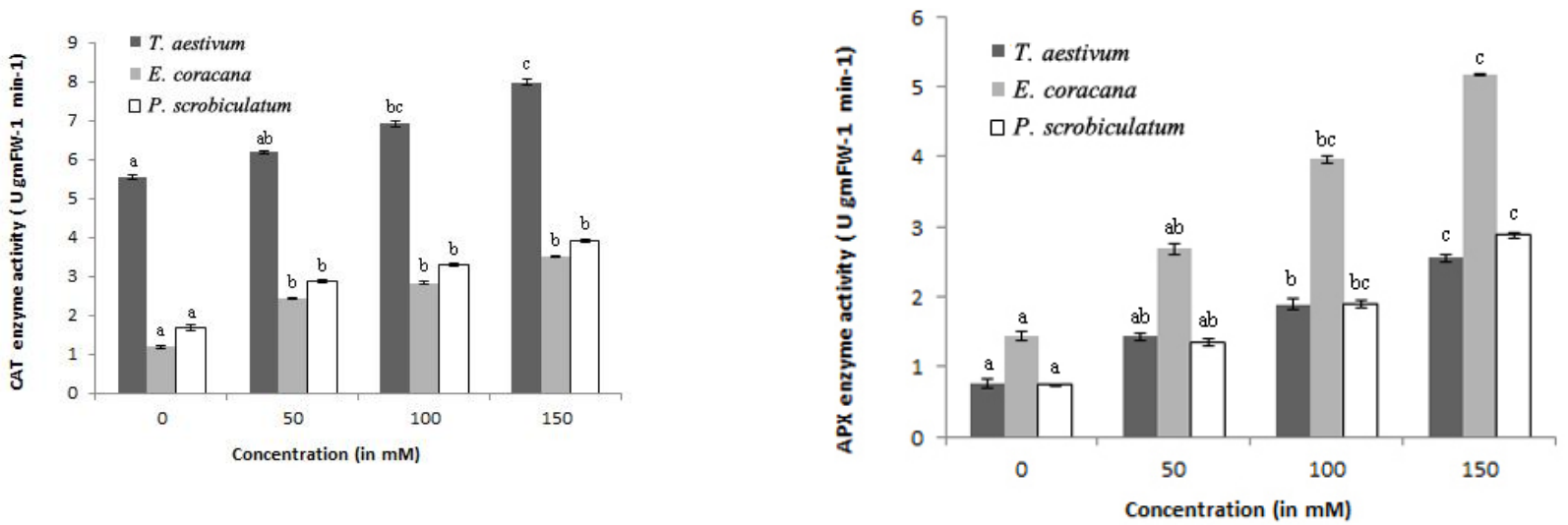

Fig 3C

Fig 3D

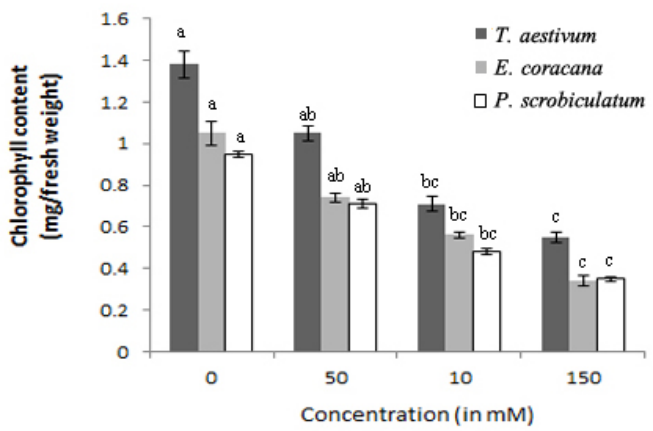

Fig 3E

Fig. 3: Enzyme activities of plants under different salt concentrations.

$\begin{array}{lllll}\text { A. SOD } & \text { B. CAT } & \text { C. POX } & \text { D. APX } & \text { E. Total Chlorophyll content }\end{array}$ (Values followed by different letters are significantly different at a significance level of $p \leq 0.05$ )
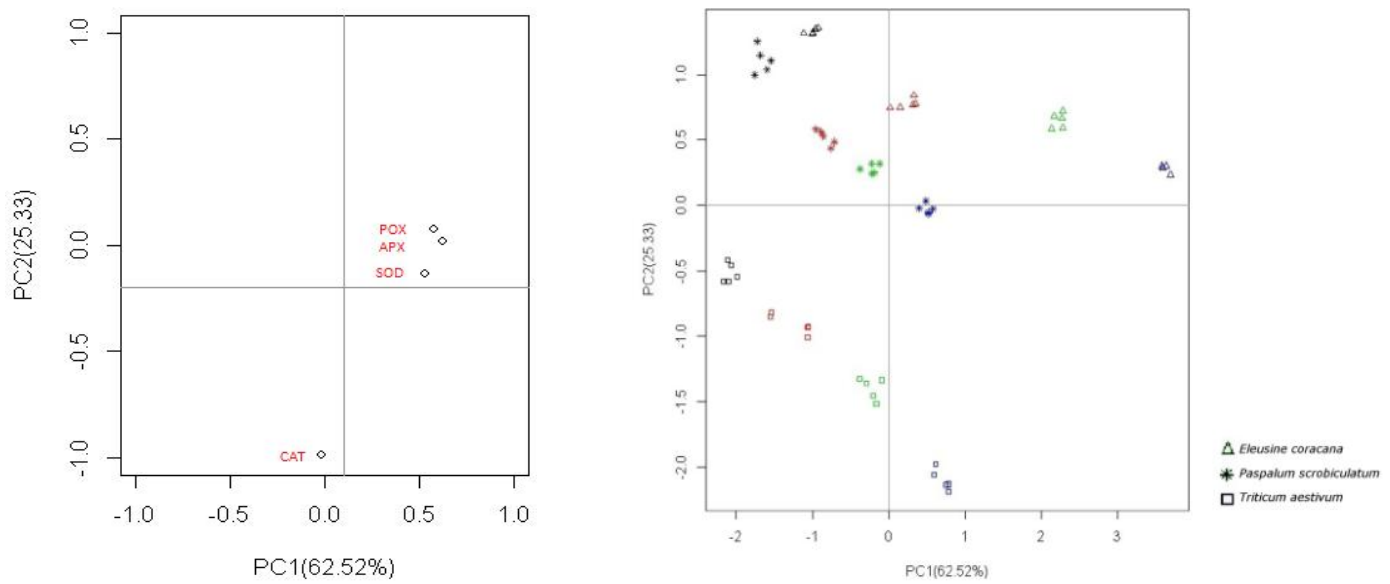

Fig. 4: A and B: PCA loadings and scores respectively of the first two PCs obtained for the combined shoot dataset of Triticum, Eleusine and Paspalum. In Fig $4 \mathrm{~B}$, black, red, green and blue represents $0 \mathrm{mM}, 50 \mathrm{mM}, 100 \mathrm{mM}$ and $150 \mathrm{mM}$ salt concentration respectively.

\subsection{Dose Response Analysis}

C50 values for salinity driven reduction in shoot length were determined by "drc" package and it was observed that Eleusine showed the highest C50 value i.e. $216.16 \mathrm{mM}$, followed by Paspalum and Triticum with C50 values of $137 \mathrm{mM}$ and 123.03 $\mathrm{mM}$ respectively $(\mathrm{P} \leq 0.05)$.

\subsection{Principal Component Analysis}

PCA of the combined data set yielded four significant PCs. Two PCs were selected according to Kaiser's criterion (1960) which represented $87.85 \%$ of the total data variance. Fig $4 \mathrm{~A}$ and
$\mathrm{B}$ respectively, represent the loadings and score of first two PCs i.e. $\mathrm{PC} 1$ and $\mathrm{PC} 2$ which epitomize the main grouping in the combined data set. In fig 4 A, the PC1 is largely determined by SOD, APX and POX with strong positive loadings, grouping in the upper right quadrant. CAT showed the only negative loading in PC1 so this component gets culled on the one side and on the flip side, the rest of the variables are clubbed together (SOD, APX and POX), whereas in PC2, only POX and APX showed positive loadings. The score plot (fig 4 B) also suggested an appreciable contrast amidst the three plants grouping them into three visible clusters. 

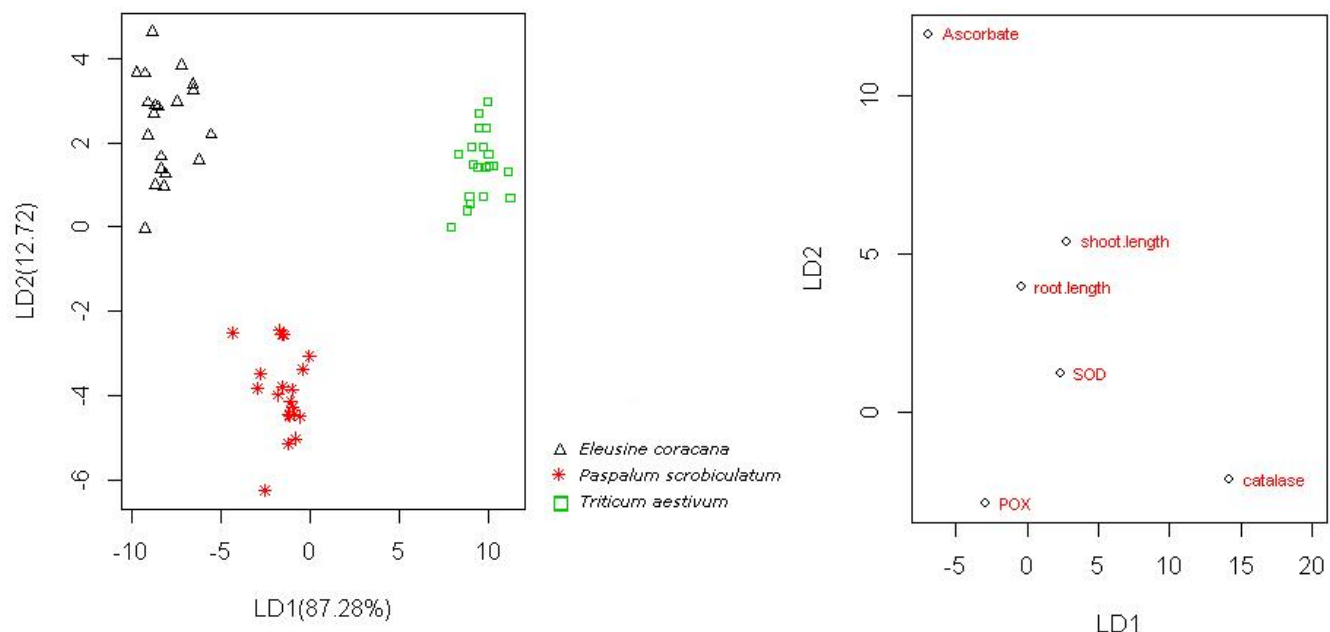

Fig. 5: A and B: coefficient and scaling graph respectively.

\subsection{Linear Discriminate Analysis}

Variations in plant response to salt stress in terms of morphological and biochemical parameters was measured in the three plants and further evaluated through Linear discriminate analysis (LDA). LDA was performed on combined standardized dataset $(\log +1$ transformation). We obtained two linear discriminates which explain $99.3 \%$ of variation in combined dataset. Manova was done for our model and this was tested with Wilks test and lambda value equaling 0.0033 with $p$ value $2.2 \mathrm{e}-16$ at a 0.001 significance level was obtained, thereby proving that our model is significant and cannot be rejected. The coefficient and scaling graph for two linear discriminate functions i.e. LD1 and LD2 is plotted in fig $5 \mathrm{~A}$ and $\mathrm{B}$.

\section{DISCUSSION}

The diminished supply of nutrients to the root with enhancement in salinity levels, contributes significantly to the decrease in mean root length as they are the first organs exposed to saline environment. The noticed results were in agreement with studies conducted by [19], who suggested that it may be due to reduction in turgor of the radicle cells. [20] studied 20 different wheat varieties and indicated that the shoot dry matter was affected more as compared to root to greater levels by increasing salinity amounts referring to the increase in osmotic pressure, resulting in poor water uptake and hence hindering the overall seedling growth.

The relative germination rate was found to be highest in Eleusine when compared with Triticum and Paspalum, at all the concentrations of salt in the medium respectively, suggesting that the millet species can thrive relatively well than the other two plants. Germination index is one of the best methods to understand the plant's response to salinity as it is calculated by both total and mean germination rate of seeds after specific time duration and this parameter is seen to be decreased in all the three plants, due to increasing salinity gradients. [21] reported that high salinity levels lead to the accumulation of sodium and magnesium ions in the actively growing tissues especially those of the meristem, which in turn disturbs the regular growth mechanism and thus the cells tend to follow alternate growth pathways to protect themselves from the damage, ultimately leading to decreased germination index. The results are also in agreement with the studies conducted on six varieties of Paspalum by [22], where the salt tolerant varieties showed higher germination index and germination energy as compared to moderately tolerant and salt sensitive varieties due to aroused osmotic toxicity.

The salt concentration of $200 \mathrm{mM}$ in the medium led to diminished growth of the seedling and thereby it was difficult to extract enzymes, hence seedling from $200 \mathrm{mM}$ salt concentration were not considered for further analysis. The higher levels of SOD with increasing salinity regime, concord with studies conducted on major cereals like those on Wheat by [23] and Maize by [10] Superoxide dismutases form the first line of defense in cells and are produced in all the compartments within cells where $\mathrm{O}_{2}^{-1}$ radicals were formed [24] and water constraining conditions enhance the SOD activities.

Salt induced injury led to an increase in activities of CAT which is in agreement with studies by [10], conducted on Maize cultivars. The catalase activities elevated in wheat genotype with increasing salt levels as compared to other two plants.

Peroxidases (EC 1.11.1.7) enzymes are widely distributed in plant cells and consist of mostly glycosylated heme containing monomeric enzymes. Under conditions of restricted electron transport, their amount increases as stress elevates. The APX and POX enzyme activities were found to increase significantly in all the three plants with increasing salinity levels with the highest reported enzyme activity in E. coracana and the results were in agreement with studies conducted on two rice cultivars (salt sensitive and moderately salt tolerant) by [25]. The higher values in Eleusine suggest more efficient $\mathrm{H}_{2} \mathrm{O}_{2}$ scavenging than the other plants at higher salt concentrations which suggest that it can decompose $\mathrm{H}_{2} \mathrm{O}_{2}$ more rapidly than Triticum and Paspalum. The higher C50 value indicates Eleusine to be more salt tolerant in comparison with the other two plants. The results are in 
agreement with studies conducted by [26], who studied six varieties of pearl millet and concluded that C50 value appears as best criteria for selection of salt tolerance amongst other parameters, thereby suggesting that soil salinity tolerance is shown by the crops till their threshold level and the yield is constitutively decreased with enhancing salinity levels.

It was noted that Triticum differentiated prominently in terms of catalase in the principal component analysis whereas response in Paspalum and Eleusine was more prominent in terms of POX, APX and SOD possibly by virtue of them being millets and having a short evolutionary distance. That's why they show less divergence in their biochemical responses towards stress. The fig 4B also coops up finger millet in the extreme corner, signifying its higher response towards salinity amongst the three plants in consideration.

The reason of the disparate reactivity of peroxidases and catalase is not still known, but structural differences amongst their heme active sites like peroxidases exhibiting an open and solventexposed active site, whereas the heme of catalases is deeply buried into the protein with its access channel being long and narrow, could be the probable reason for contrasting response towards stress [27]. Catalases are the only class amongst scavenging enzymes for reactive oxygen intermediates, which are located in peroxisomes and their role is indispensable when the peroxisomes proliferate during stress conditions [28].The study is in accordance with work of [29] who stated that high rate of photorespiration and perturbation of foliar antioxidant system, increases amount of $\mathrm{H}_{2} \mathrm{O}_{2}$ which is rapidly removed by catalases, thereby leading to enhancement in catalase production by wheat under abiotic stress. The LDA results suggests that the LD1 which accounts for $87.28 \%$ variation has high coefficient value for catalase, so catalase is the most significant parameter to discriminate between the three plants exposed to salt which means that this parameter accounts for most of the expected variation in the biochemical parameters. LDA's two functions are adequate in discriminating the plants into different groups and prove as an important tool for classifying plants based on their salinity potential.

\section{CONCLUSION}

To conclude, the present study elucidates the responses of plants used across the globe for feed and fodder under varied salinity regimes. Alleviation in the discrete ROS production was reported in all the three plants species i.e. Triticum aestivum, Eleusine coracana and Paspalum scrobiculatum and the small millet 'Eleusine' exhibited the superlative response under entire salt spectrum. The salt-induced oxidative stress was further investigated using Multivariate modeling (LDA, PCA). The Multivariate analysis thus identified the significant biochemical variables responsible for the inequity among these three plant species and those of relatively higher significance as induced in the plants under the stress conditions. This study shows that application of the multivariate modeling techniques to the complex biochemical datasets obtained through plant nutrition and physiological research and can facilitate the interpretation and visualization of the interrelationships of the variables.

\section{ACKNOWLEDGEMENTS}

Junior research fellowships to Ritika Bhatt (DBT-IPLS), Prem Prakash Asopa (CSIR), Santosh Sihag (UGC) and RAship to Rakesh Sharma (DBT-BIF) are gratefully acknowledged.

\section{REFERENCES}

1. Vahdati K., Leslie C. Abiotic stress-plant responses and applications in agriculture. InTech. 2013; 1: 418.

2. Ashraf, M., 2009. Biotechnological approach of improving plant salt tolerance using antioxidants as markers. Biotechnology Advances 27: 84-93.

3. Lewis, D.H. Storage carbohydrates in vascular plants: distribution, physiology and metabolism. (London: Cambridge University Press). 1984.

4. Munns, R., Tester, M. Mechanisms of salinity tolerance. Annual Review of Plant Biology. 2008; 59: 651-81.

5. Ashraf, M. Biotechnological approach of improving plant salt tolerance using antioxidants as markers. Biotechnology Advances. 2009; 27: 84-93.

6. Zhu, J.K. Salt and drought signal transduction in plants. Annual Review of Plant Biology. 2002; 53: 247-73.

7. Meloni, D.A., Oliva, M.A., Martinez, C.A., Cambraia, J. Photosynthesis and activity of superoxide dismutase, peroxidase and glutathione reductase in cotton under salt stress. Environmental and Experimental Botany. 2003; 49: 69-76.

8. Neto, A.D.A., Prisco, J.T., En'eas-Filho, J., Abreu, C.E.B., GomesFilho, E. Effect of salt stress on antioxidative enzymes and lipid peroxidation in leaves and roots of salt-tolerant and salt-sensitive maize genotypes. Environmental and Experimental Botany, 2006; 56: 87-9.

9. Papadimitriou, V., Sotiroudis, T.G., Xenakis, A., Sofikiti, N., Stavyiannoudaki, V., Chaniotakis, N.A. Oxidative stability and radical scavenging activity of extra virgin olive oils: An electron paramagnetic resonance spectroscopy study. Analytica Chimica Acta. 2006; 573: 453-458

10. Hussain, I., Ashraf, M.A., Anwara, F., Rasheed, R., Niaz, M., Wahid, A. Biochemical characterization of maize (Zea mays L.) for salt tolerance. Plant Biosystems-An International Journal Dealing with all Aspects of Plant Biology. 2014; 148: 1016-1026.

11. Ediga, A., Hemalatha, S., Meriga, B. Effect of salinity stress on antioxidant defense system of two finger millet cultivars (Eleusine coracana (L.) Gaertn) differing in their sensitivity. Advances in Biological Research. 2013; 7: 180-187.

12. Racusen, D., Foote, M. Protein synthesis in the dark grown bean leaves. Canadian Journal of Botany. 1965; 817-824.

13. Dhindsa, R.S., Plumb-Dhindsa, P., Thorpe, T.A. Leaf senescence: correlated with increased levels of membrane permeability and lipid peroxidation, and decreased levels of superoxide dismutase and catalase. Journal of Experimental Botany. 1981; 126: 93-101.

14. Teranishi, Y., Tanaka, A., Osumi, M., Fukui, S. Catalase activities of hydrocarbon utilizing Candida yeasts. Agricultural and Biological Chemistry. 1974; 38: 1213-1220.

15. Nakano, Y., Asada, K. Hydrogen peroxide is scavenged by ascorbate-specific peroxidase in spinach chloroplasts. Plant and Cell Physiology. 1981; 22: 867-880.

16. Maclachalan, S., Zalic, S. Plastid structure, chlorophyll concentration and free amino acid composition of a chlorophyll mutant on barley. Canadian Journal of Botany. 1963; 41: 1053-1062.

17. Gomez, K.A., Gomez, A.A. Statistical procedure for agricultural research ( $2^{\text {nd }}$ edition), John wiley, NY. 1984; 680.

18. Ritz, C., Streibig, J.C. Bioassay analysis using R. Journal of Statistical Software, 2005; 12: 1-22. 
19. Bewley, J.D., Black, M. Seeds: physiology of development and germination. Plenum press, New York and London, $2^{\text {nd }}$ edition. 1994;147.

20. Shekoofa, A., Bijanzadeh, E., Emam, Y., Pessarakli, M. Effect of salt stress on respiration of various wheat lines/cultivars at early growth stages. Journal of Plant Nutrition. 2013; 36, 243-250.

21. Khan, H.A., Ayub, C.M., Pervez, M.A., Bilal, R.M., Shahid, M.A., Ziaf, K. Effect of seed priming with $\mathrm{NaCl}$ on salinity tolerance of hot pepper (Capsicum annuum L.) at seedling stage. Soil and Environment. 2009; 28: 81-87.

22. Kumari, R., Vishnuvardhan, Z., Babu, K. A study on effect of $\mathrm{NaCl}$ stress on Kodomillet (Paspalum scrobiculatum) during germination stage. Annals of Plant Sciences. 2013; 2, 388-394.

23. Haouari, C., Nasraoui, A., Carrayol, E., Gouia, H. Response of two wheat genotype to long-term salinity stress in relation to oxidative stress and osmolyte concentration. Cereal Research Communications. 2013; 41: 388-399.

24. Alscher, R.G., Erturk, N., Heath, L.S. Role of superoxide dismutases (SODs) in oxidative stress in plants. Journal of Experimental Botany. 2002; 53: 1331-1341.

25. Lee, M.H., Cho, E.J., Wi, S.G., Bae, H., Kim, J.E., Cho, J.Y., Lee, S., Kim, J.H., Chung, B.Y. Divergences in morphological changes and antioxidant responses in salt-tolerant and salt-sensitive rice seedlings after salt stress. Plant Physiology and Biochemistry. 2013; 70: 325335 .
26. Muhammad, A.G., Murtaza, N., Collins, J.C., McNeilly, T., 2006. Study of salt tolerance parameters in pearl millet Pennisetum americanum L. Journal of Central European Agriculture 7: 365-376.

27. Vidossich, P., Alfonso-Prieto, M., Rovira, C. Catalases versus peroxidases: DFT investigation of $\mathrm{H}_{2} \mathrm{O}_{2}$ oxidation in models systems and implications for heme protein engineering. Journal of Inorganic Biochemistry. 2012; 117: 292-297.

28. Mittler, R. Oxidative stress, antioxidants and stress tolerance. Trends in Plant science. 2002; 7: 405-410.

29. Luna, C.M., Pastori, G.M., Driscoll, S., Groten, K., Bernard, S., Foyer, C.H. Drought controls on $\mathrm{H}_{2} \mathrm{O}_{2}$ accumulation, catalase (CAT) activity and CAT gene expression in wheat. Journal of Experimental Botany. 2005; 56: 417-423.

30. Li, Y. Effect of salt stress on seed germination and seedling growth of three salinity plants. Pakistan Journal of Biological Sciences. 2008; 11 : 1268-1272.

\section{How to cite this article:}

Bhatt R, Asopa PP, Sihag S, Sharma R, Kachhwaha S and Kothari SL. Comparative three way analysis of biochemical responses in cereal and millet crops under salinity stress. J App Biol Biotech, 2015; 3 (06): 022-028. DOI: 10.7324/JABB.2015.3604 